
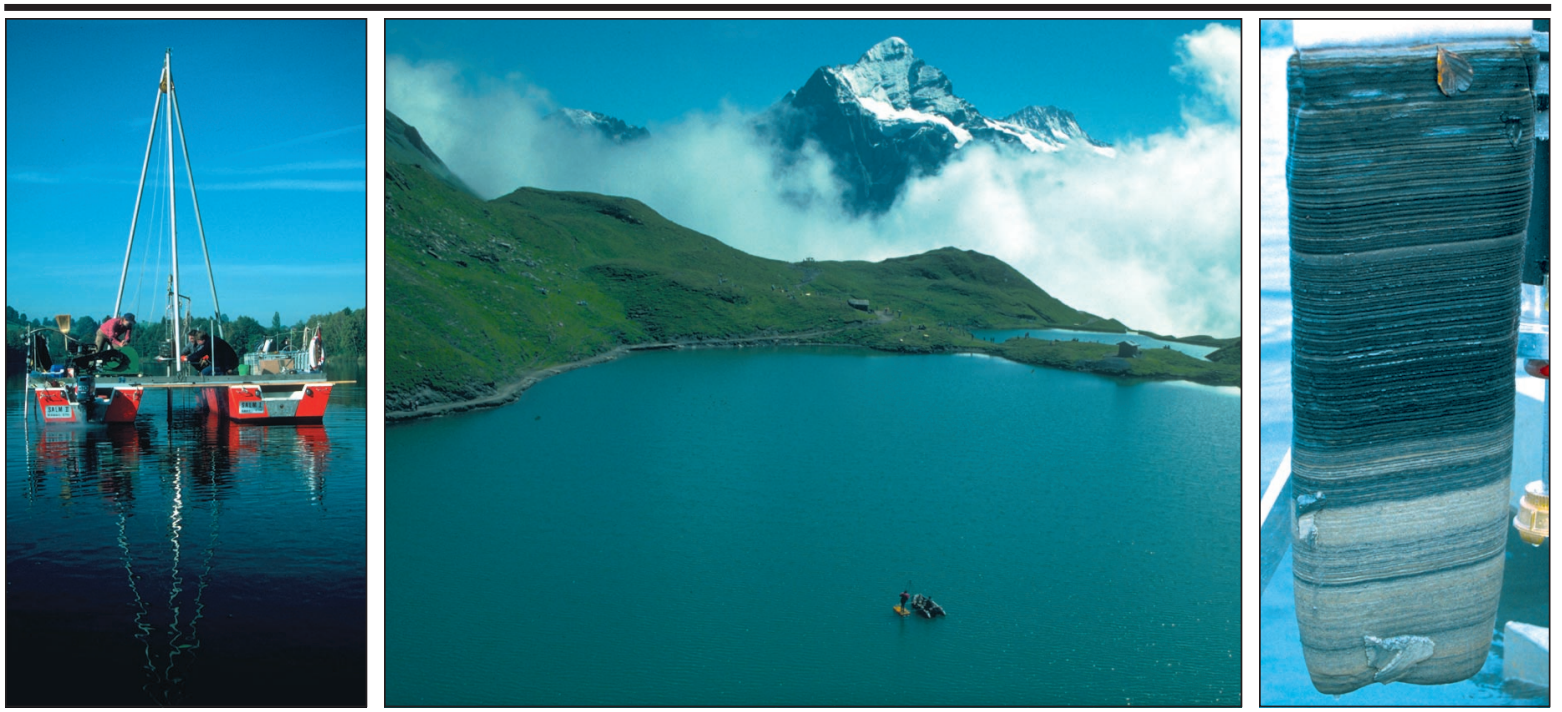

One of the major themes in the present newsletter is lakes - both as part of the full range of continental aquatic sytems ( $p p$ 2-3) and as sources of sedimentary records ( $p p$ 12-16). These pictures illustrate different forms of lake coring on Swiss lakes (from left to right): on Soppensee with a piston corer from a drilling platform; on Bachalpsee with a gravity corer; a freeze core with annually laminated sediments from Baldeggersee. For more information check the University of Bern's Paleolimnology group homepage: http:/ / www.cx.unibe.ch/sgi/paleolimnology.html (Photos: A.F. Lotter).

\title{
EDITORIAL
}

\section{PAGES Synthesis}

Over the next two to three years, a major responsibility of the IGBP will be to produce a synthesis of the program achievements to date. PAGES plans both to develop its own project synthesis and to contribute to the IGBP-wide task.

The intention, within PAGES, is to produce a book in the IGBP series, as well as an executive summary in the form of a glossy brochure, both to be published early in 2001. The first steps have already been taken. A draft outline of the themes around which the summary brochure will be organized has been the subject of an ongoing electronic discussion forum on the PAGES website and the format of the book itself is beginning to take shape. The goal must be to create a thematically oriented synthesis rather than a compilation of PAGES-related research. This means that in its organization, the synthesis will transgress the Foci and Activities listed in the PAGES Implementation Plan, rather than summarize in succession the research completed within each of them. It will thus be complementary to the more 'bottom-up' syntheses of individual components of the PAGES project and will not conflict with current and future initiatives like the PEP I synthesis currently being coordinated by Vera Markgraf in the wake of the landmark meeting in Merida last March. Nor will it replicate the approach taken in compiling the special issue of Quaternary Science Reviews that will stand as a record of the oral presentations at the PAGES Open Science Meeting. The latest outline of the synthesis themes is designed to set the process in motion with a small group of co-ordinators, rather than to prescribe the eventual structure of the book to be produced. The first meeting of a synthesis planning group was held in San Francisco in December 1998. The themes identified by the group as the basis for the next stage in PAGES

1 Editorial PAGES Synthesis

2 Program News Continental Aquatic Systems, PEP I, IMAGES, PEP III, ADVANCE 1OK, PANGAEA

11 Obituary In Memory of Hans Oeschger

12 Lakes Large Lake Records, LDTF, African Crater Lakes, ELDP

17 Workshop Reports BIOME 6000

18 Announcements START Young Scientist Awards, PAGES Grants for Summer School, Inter-PEP Workshop

19 Inside PAGES Changes in PAGES SSC, PAGES Workshop Support

20 Last Page Calendar 


\section{The Potential Role of PAGES in the IGBP Water Initiative}

synthesis, and the co-ordinators associated with each theme are as follows:

1. The human rationale for the study of past environmental change (Oldfield).

2. The course of past climate change (Bradley).

3. Forcings and feedbacks operating on the physical climate system (Stocker/Alverson).

4. Biogeochemical/biospheric aspects and impacts of past global change (Boyle/Overpeck).

5. Future directions - this section will require input from all the others, as well as from senior colleagues external to the process. Jean-Claude Duplessy and Claude Lorius have agreed to share this responsibility.

The timetable proposed follows on from the brief workshop at the Fall AGU attended by several of the initial $\mathrm{CO}^{-}$ ordinators and other members of the PAGES community who were on the spot. Sub-group meetings are planned for the first 4 months of 1999 to shape and refine the contents of each section. The IGBP Congress in May 1999 will provide an opportunity to collate, present and evaluate the outlines of the book. At that stage, the shape and content will be endorsed by the PAGES Scientific Steering Committee (SSC). The next stage will be the main phase of writing, culminating in a final workshop to tie the whole text together during 2000. Ideally, both the book and certainly the glossy Executive Summary booklet should be available for the IGBP Open Science Meeting planned for Spring 2001. Towards the end of this period, we anticipate that the PAGES SSC will begin to review the status and future of the PAGES project as part of a broader review of IGBP as a whole.

The task of synthesis presents the PAGES community with a major challenge; perhaps the most daunting one yet. We shall try to keep the wider PAGES community abreast of the process through the newsletter and the website and we welcome your views on the scope, purpose and optimal outcome of the synthesis process.

\section{Frank Oldfield}

Executive Director, PAGES IPO, Bern, Switzerland oldfield@pages.unibe.ch

\section{A Proposed Integrative Inter-Project Inititative on Continental Aquatic Systems}

The primary goal of this initiative, as defined in the document approved by the IGBP SC, is to understand the role of continental aquatic systems in global biogeochemical cycles. The overarching question posed at the outset is: How have continental aquatic systems and the nutrient fluxes associated with them been and will be influenced by and responsive to global change, over past, present, and future time frames? Continental aquatic systems are defined as all surface and subsurface water involved in the hydrologic cycle on the continents. This includes lakes, rivers, wetlands, soil moisture, and ground water from the point where precipitation reaches the earth's surface until it reaches the sea in full marine conditions, or until it reaches some other final base level. The "downstream" boundary is a broad zone variable in space and time wherein river water interacts with the ocean before reaching fully marine characteristics with respect to chemistry and ecology. The emphasis of the project will be on water, sediment, carbon, nitrogen, phosphorus, silicon and micro nutrients.

\section{Past Biogeochemistry and Paleoecology}

Continental aquatic systems are rich in natural archives of past biogeochemical states and fluxes. These take the form of lake, reservoir and near-shore marine sediments, ground waters and accumulated wetland sediments and peats. Analyses of such archives can provide insight into both the past biogeochemistry of the systems studied and of the changing conditions of climate, vegetation, soils and human land use to which changes in aquatic biogeochemistry are linked. They can document the impact of biogeochemical changes on the nature and functioning of aquatic ecosystems in the past. In addition, paleo-records can provide information on the pristine state of drainage basins which are now severely altered by human activity, and thus out of biogeochemical and ecological equilibrium.

Currently available evidence suggests that even in long-settled and highly developed areas of the world, (e.g. Western Europe), the main changes in aquatic biogeochemistry have taken place within the last 150 to 200 years, despite the fact that agriculture, deforestation and local settlement began centuries and, in many cases, millennia before this. The main initial forcing factors seem to have been population growth, urbanization, industrial development and the construction of integrated sewer systems. Current forcing increasingly reflects the impact of nonpoint agricultural sources for $\mathrm{N}$ and $\mathrm{P}$. It may be that further evidence from longsettled areas, in Eurasia and the Mediterranean region for example, will build a case for a more flexible time frame, but we believe that the main focus should be on the last 200 years. This has the added advantage of being compatible with the time frame prioritized by LUCC and GCTE for reconstructing past land cover and terrestrial ecosystems. Moreover, chronologies of sedimentation can often be provided for most of this period, using radiometric techniques such as ${ }^{210} \mathrm{~Pb}$. There are also opportunities for quantitative calibration over this time interval, through comparison with direct observations during the most recent period.

Recent research confirms that paleolimnological studies can track past atmospheric contamination using the record of metal and fly ash deposition. The fossil record in the sediments can be used as a basis for reconstructing past water quality, including changes in $\mathrm{pH}$, with a high degree of precision. It can also be used to reconstruct past $\mathrm{P}$ loadings to a reasonable level of approximation. More research is required to establish the degree of confidence with which it may become possible to reconstruct past changes in $\mathrm{N}$ and $\mathrm{Si}$ concentrations and fluxes from sedimentary evidence. Records of past particulate inputs are often extremely well preserved in and quantifiable from the sedimentary record and these are of special importance where nutrient delivery and sequestration are particle-associated. At the same time, sediment studies allow calculation of bulk catchment yields and sediment source ascription in ways that can be directly related to soil and terrestrial ecosystem processes, such as accelerated erosion and deforestation.

\section{Lake Sediments and Past Climate}

There is growing evidence to show that paleolimnological research can provide robust reconstructions of climate varia- 